\title{
Attitude Teaching Structure Research of Advanced Mathematics Based on Activities of Mosoteach
}

\author{
Dai Guoxing, Zhao Jiazhen, Li Yaopeng, Tao Zhengrong \\ College of Science, Jiangsu University Mathematics and Applied Mathematics Major 212013
}

Keyword: Attitude Teaching; Student input; Educational data mining

\begin{abstract}
Based on the cloud teaching, this paper collects data for college mathematics teaching and constructs students' learning input model to analyze the students' learning. The relationship between student input and learning, teaching and evaluation is analyzed by data model. Through the analysis of the structure of attitude teaching, teachers' understanding of students' learning mode is deepened, which provides reference for the improvement of teaching mode and evaluation mode.
\end{abstract}

Attitude is the basic entity of three learning fields, including cognitive field, psychogenic movement field and emotion field ${ }^{[1]}$ (Thomas F.Kamradt \& Elisabeth J.Kamradt proposed the structural design of attitude teaching). In practice, we usually think that the cognitive, psychogenic, and emotional components constitute the attitude, and the internal attitude of learners, stored together with the subject content, becomes a tool for implementing unique individual strategies. The digital education resource evaluation under the mixed teaching and learning mode not only focuses on the resource itself, but also pays more attention to the user's activities in the resource application. The application activities are recorded as the element of evaluation, which can reflect the user's actual use behaviors more truly. Therefore, the development and utilization of innovative curriculum resources of advanced courses in higher mathematics should not only focus on the resource development technology itself, but also focus on the activities attached to the resources, and pay attention to and evaluate the activity ability of users to use the resources. In this attitude, by using the Mosoteach after class to implement data mining for the evaluation of learning, learning diagnosis is given a prescription, to achieve the strategies and methods of knowledge management, observing and analyzing the structure of teaching attitude, positive input model and attitude of learning higher mathematics teaching consistency, explore the practice of college students' personal cultivation and the improvement of learning ability.

\section{Research Status and Development Trend at Home and Abroad}

With the expansion of education scale, the country's investment in education increases, the society and the public pay more and more attention to the talent cultivation in colleges and universities, but the fact is that some students' enthusiasm in learning investment is decreasing. Studies have shown that one of the most immediate and persistent problems in education practice are student engagement. This study uses the data of cloud teaching to analyze the relationship between student input and learning effect.

Student input is the student's input to study time and energy.

In the 1930s, Tyler, an education psychologist, first came up with the concept of "student engagement," which he defined as "time spent on tasks," describing the amount of time students spend on learning and how this amount influences learning outcomes.

In the 1960s, Pace used "student engagement" to describe the quality of student effort, and developed a study experience questionnaire. In a 30-year study, Pace found that students benefited more when they put in more time and energy to engage in activities that require high levels of effort.

The theory of student input in modern sense was first proposed by Astin in 1984, and the theory of student input proposed by Astin contains five basic assumptions. First, input refers to the physical strength and energy invested in a certain object. Second, for the same object, different students have different levels of involvement. Third, the input has both quantity and quality. Fourth, students' academic performance and personal development level are directly related to the quantity and quality of students' input. Fifth, the education policy or practice effect of the school is directly related to student input. At the 
same time, Astin proposed the i-e-o model to describe the student Input theory, in which I(Input), $\mathrm{E}$ (Environment) and $\mathrm{O}$ (Output) showed that the students' learning development was the result of three interrelated factors influencing each other.

On the basis of Astin, George Kuh study and think students into refers to the students to join in an activity of time and energy, as well as the school environment and affect the students create relevant behavior, it has further improved student investment theory, make the theory contains two aspects: one, the influence of the school environment as well as to the students is the key factor; two, individual efforts and time and energy input of students are the main factors ${ }^{[2]}$.

In terms of the theoretical research on student engagement, the research content mainly includes students' learning experience and learning status. At present, internationally famous research surveys include the "NSSE" and "SERU" in the US, the "NSS" in the UK, and the "CEQ" in Australia ${ }^{[3]}$.

At present, China has begun to pay attention to the research on this aspect. Relevant researches include: Tsinghua University's survey on the study investment of Chinese university students by introducing American NSSE, Beijing university's survey on the development status of students in capital universities, "undergraduate study experience survey" carried out by Nanjing University, xi 'an Jiaotong University, Hunan University, and "national undergraduate study investigation" conducted by Xiamen University ${ }^{[4-8]}$.

With the development of education in higher education, many universities are paying more and more attention to the study of student input. It is believed that the study of student input will be paid more and more attention by teachers and will be helpful to the development of education in higher education.

\section{Connotation of Student Input}

What is the definition of student engagement? There is no unified answer to this question. The research tendency of each research field is different. The literature in the field of psychology tends to include motivation, attitude and thinking. The sociology domain tends to regard happiness and belonging as the core word of research investment. The education field prefers the combination of the two, emphasizing students' intellectual, psychological and social input in learning activities ${ }^{[9]}$.

Typical examples include:

In 1984, Astin explained "student engagement," defining it as "the sum of the mental and physical inputs that college students put into learning activities." ${ }^{[10]}$. This view holds that the "responsible person" of student input is the student. On this basis, have other ideas, such as "students is directly related to the required results struggling level of purposeful education activities", and "the degree of students into activities, these activities are higher education research prove that associated with the study results of high quality", both views think students into "person" is a student. But there are other ideas, such as "institutions and departments trying to engage students in the process of shaping their learning experiences," which holds that schools and institutions are responsible for student engagement. There is also a view that student input is "the time and effort of students to engage in activities related to the purpose, results and experience and the efforts of institutions to guide students to participate in these activities". This view holds that the "responsible person" of student input is Shared by students and relevant institutions.

In 2007, Kuh defined "student engagement" as "participation in effective education practices both inside and outside the classroom, and bringing about a range of measurable results". This view holds that students' input is not only the learning input in the classroom, but also the input of beneficial activities outside the classroom. Based on this, the relevant views include "student engagement is a broad concept that includes both explicit disciplinary and non-disciplinary student experience". ${ }^{[11]}$

\section{Factors Affecting Students' Input}

Student engagement is a multivariate concept, which integrates many independent factors in education to form a whole concept, which is used to describe the idea of students studying in school.

We can analyze it from two aspects: 


\subsection{The characteristics of a student's entrance}

A large number of studies have shown that high school academic achievement and behavior characteristics before entering college are related to behavior, academic performance and experience during enrollment. Therefore, it is important to examine the background and pre-school characteristics of freshmen for later teaching development ${ }^{[12]}$.

\subsection{The forms of student input}

In 1986, the committee for the promotion of higher education standards (CAS) published the first "standards and guidelines for the service and development of CAS students" (the CAS standard), and identified 16 business areas, including academic consultation, career planning and introduction, university associations, and learning assistance programs. In 1988, CAS created the self-assessment guide. In 2003, the CAS standard was expanded to 29 transaction areas and 30 self-assessment guidelines. In 2006, in addition to the original nine standards in the transactional domain, five new standards in the transactional domain were added.

CAS believes that any functional area of student affairs has identifiable commonalities, and it establishes "general standards" for those commonalities. In 2008, the standard was adjusted to 14 aspects: mission, project, leadership, human resources, ethics and ethics, legal responsibilities, equal opportunities, differences, organizational management, campus and community relations, financial resources, technology, equipment, evaluation ${ }^{[13]}$.

\section{Research Methods}

The project is to study the data from the Mosoteach, and the data collection is a class of two classes at the Jiangsu University for advanced mathematics. There were 124 students in the two classes of advanced mathematics (the first volume) and 132 students in the two classes of advanced mathematics (the second volume).

The student input model is based on the structure of "input-process-output", and Astin's i-e-o model is used as a reference to construct the student input model from the four aspects of activity participation, autonomous learning, classroom assignments and classroom efficiency ${ }^{[14-15]}$.

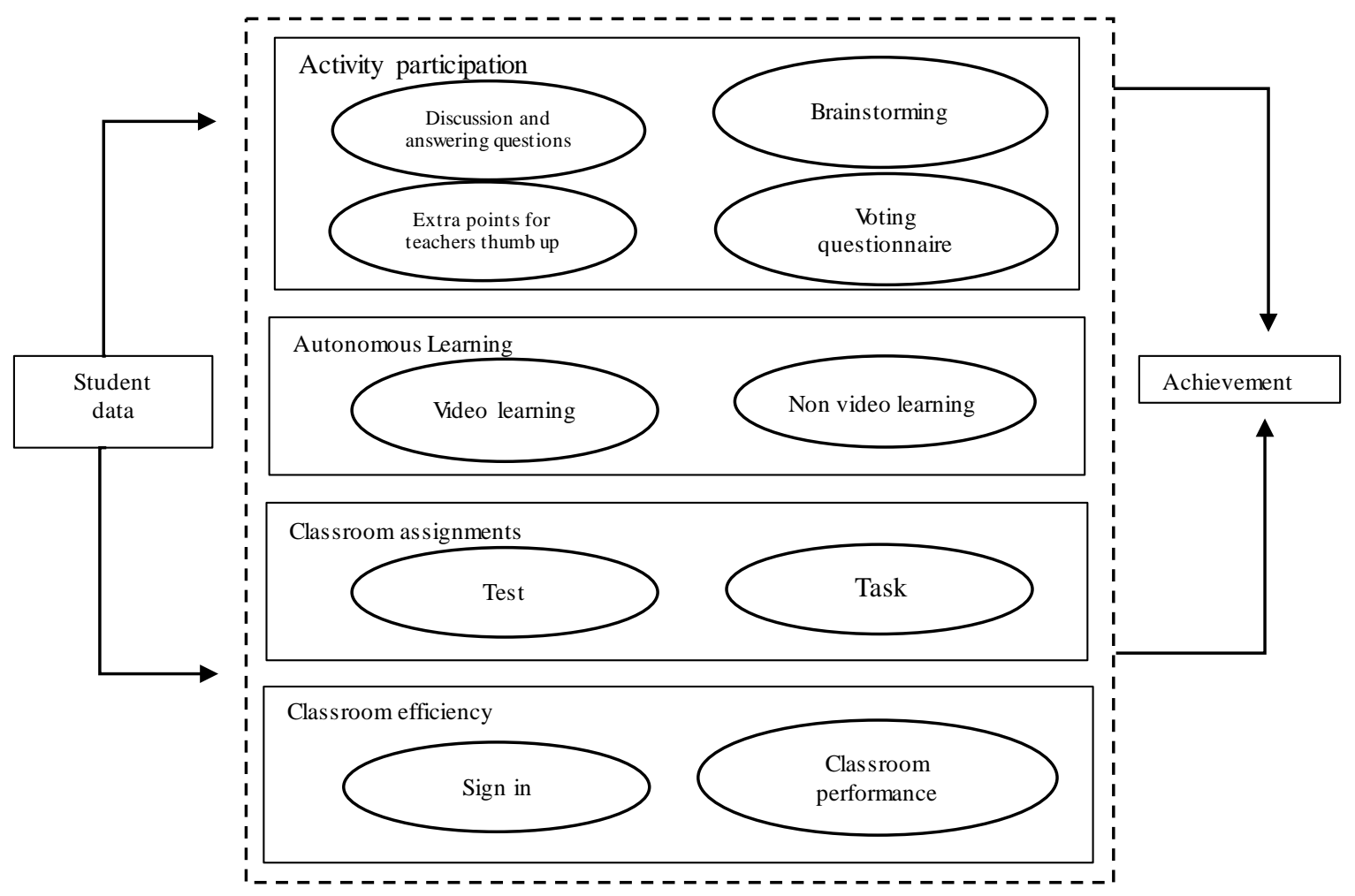

Fig.1 Framework of "input-process-output" 
The activities include discussion and answering questions, brainstorming, extra points for teachers thumb up, and voting questionnaire. Independent learning includes video resource learning and non-video resource learning. Class assignments include tests, task groups; Classroom efficiency includes check-in and classroom performance.

From the perspective of college students, this project constructed a model based on the framework of "input-process-output" and analyzed the influence of students' learning type, relevant input proportion and various factors on the final score, providing reference for the improvement of teaching evaluation in the future.

\section{Analysis of Student Input}

\subsection{Clustering and validating weights of factors affecting performance}

To guarantee the factors contributing to learning input have reasonable weight distribution, grading the factors affecting performance according to the 1-9 scale tables and recalculating weights of them under the extant weight distribution of teaching evaluation.

Table 1 Original weight assignment

\begin{tabular}{|c|c|c|c|c|c|c|c|c|c|}
\hline $\begin{array}{c}\text { Video } \\
\text { resource } \\
\text { learning }\end{array}$ & $\begin{array}{c}\text { Non-video } \\
\text { resources }\end{array}$ & $\begin{array}{c}\text { Sign } \\
\text { in }\end{array}$ & Test & $\begin{array}{c}\text { Discussion } \\
\text { and } \\
\text { answering } \\
\text { questions }\end{array}$ & Brainstorming & $\begin{array}{c}\text { Voting } \\
\text { questionnaire }\end{array}$ & $\begin{array}{c}\text { Group’s } \\
\text { tasks }\end{array}$ & $\begin{array}{c}\text { Classroom } \\
\text { performance }\end{array}$ & $\begin{array}{c}\text { points for } \\
\text { teachers } \\
\text { thumb up }\end{array}$ \\
\hline $10 \%$ & $10 \%$ & $10 \%$ & $15 \%$ & $5 \%$ & $5 \%$ & $10 \%$ & $15 \%$ & $15 \%$ & $5 \%$ \\
\hline
\end{tabular}

Table 2 Meaning of 1-9 Scale table

\begin{tabular}{|c|l|}
\hline Scale $a_{i j}$ & \multicolumn{1}{c|}{ Meaning } \\
\hline 1 & $C_{i}$ and $C_{j}$ have the same effect \\
\hline 3 & $C_{i}$ has a slightly stronger impact than $C_{j}$ \\
\hline 5 & $C_{i}$ has a stronger impact than $C_{j}$ \\
\hline 7 & $C_{i}$ has a obviously stronger impact than $C_{j}$ \\
\hline $2,4,6,8$ & $C_{i}$ has a absolutely stronger impact than $C_{j}$ \\
\hline $1,1 / 2,1 / 3,1 / 4 \cdots 1 / 9$ & $\begin{array}{l}\text { The ratio of the influence of } C_{i} \text { to } C_{j} \text { is between the two } \\
\text { adjacent levels mentioned above. }\end{array}$ \\
\hline
\end{tabular}

Table 3 Meanings of symbols

\begin{tabular}{|l|l|}
\hline \multicolumn{1}{|c|}{$C_{i}, C_{j}$} & Factors affecting final performance \\
\hline$P_{i}$ & Types of student input \\
\hline$a_{i j}$ & Two types of comparative grade \\
\hline CI & Consistency index \\
\hline RI & Stochastic consistency index \\
\hline CR & Consistency ratio \\
\hline $\mathrm{W}$ & Weight vector \\
\hline
\end{tabular}

\subsubsection{Grading according to percentage of all types in total results}

Remember $5 \%$ as 1 , remember $10 \%$ as 2 , and remember $15 \%$ as 3 .

Table 4 Factor grade

\begin{tabular}{|c|c|c|c|c|c|c|c|c|c|}
\hline $\begin{array}{c}\text { Video } \\
\text { resource } \\
\text { learning }\end{array}$ & $\begin{array}{c}\text { Non-video } \\
\text { resources }\end{array}$ & $\begin{array}{c}\text { Sign } \\
\text { in }\end{array}$ & Test & $\begin{array}{c}\text { Discussion } \\
\text { and } \\
\text { answering } \\
\text { questions }\end{array}$ & Brainstorming & $\begin{array}{c}\text { Voting } \\
\text { questionnaire }\end{array}$ & $\begin{array}{c}\text { Group’s } \\
\text { tasks }\end{array}$ & $\begin{array}{c}\text { Classroom } \\
\text { performance }\end{array}$ & $\begin{array}{c}\text { Extra } \\
\text { points for } \\
\text { teachers } \\
\text { thumb up }\end{array}$ \\
\hline 2 & 2 & 2 & 3 & 1 & 1 & 2 & 3 & 3 & 1 \\
\hline
\end{tabular}

Next, cluster the ten categories. The factors that affect the performance are summed up as four kinds of learning input. Get the weight assignment of the four learning inputs in the original data:

$\mathrm{P}_{1}$ : Classroom efficiency (Sign in; Classroom performance) 
$\mathrm{P}_{1}=5$, weight 0.25

$\mathrm{P}_{2}$ : Classroom assignments (Test; Task)

$\mathrm{P}_{2}=6$, weight 0.3

$\mathrm{P}_{3}$ : Autonomous Learning (Video resource learning; Non video learning)

$\mathrm{P}_{3}=4$, weight 0.2

$\mathrm{P}_{4}$ : Activity participation (Discuss the answer; Brainstorming; Teacher's praise; Voting questionnaire) $\mathrm{P}_{4}=5$, weight 0.25

Remember as: $\mathrm{w}^{(2)}=\left(\mathrm{P}_{1}, \mathrm{P}_{2}, \mathrm{P}_{3}, \mathrm{P}_{4}\right)=(0.25,0.3,0.2,0.25)$

5.1.2 Establish the pairwise comparison matrix $A$

The four categories of influencing factors after clustering only to make the comparison of strength and weakness easier. Recalculating the weights of the four kinds of weight and verify them by the pairwise comparison matrix of analytic hierarchy process. Get the pairwise comparison matrix A

$$
\begin{aligned}
& \mathrm{A}=\left(\begin{array}{cccccc}
1 & 2 & & & k-1 & \\
& a_{11} & a_{12} & & a_{1 k-1} & a_{1 k} \\
& a_{21} & a_{22} & \cdots & a_{2 k-1} & a_{2 k} \\
& \vdots & & \ddots & \vdots & 1 \\
a_{(k-1) 1} & a_{(k-1) 2} & \ldots & a_{(k-1)(k-1)} & a_{(k-1) k} \\
a_{k 1} & & a_{k 2} & & a_{k(k-1)} & a_{k k}
\end{array}\right) \begin{array}{c}
k-1 \\
k
\end{array} \\
& =\left[\begin{array}{cccc}
1 & 1 / 3 & 3 & 1 \\
3 & 1 & 5 & 3 \\
1 / 3 & 1 / 5 & 1 & 1 / 3 \\
1 & 1 / 3 & 3 & 1
\end{array}\right]
\end{aligned}
$$

Calculating the largest eigenvalue of the matrix $\lambda=4.0435$, eight $w^{(1)}=(0.1998,0.5222,0.0781,0.1998)$

5.1.3 Consistency check

The pairwise comparison matrix is not usually uniform matrix, but to use its eigenvectors corresponding to $\lambda$. As weight vector of the comparison factor, as long as the degree of inconsistency is within a certain range of error.

Defining $\mathrm{CI}=\frac{\lambda-n}{n-1}$ as consistency index, the number of stochastic consistency index RI is on the following table:

Table 5 Numbers of stochastic consistency index RI

\begin{tabular}{|c|c|c|c|c|c|c|c|c|c|c|c|}
\hline $\mathrm{n}$ & 1 & 2 & 3 & 4 & 5 & 6 & 7 & 8 & 9 & 10 & 11 \\
\hline $\mathrm{RI}$ & 0 & 0 & 0.58 & 0.90 & 1.12 & 1.24 & 1.32 & 1.41 & 1.45 & 1.49 & 1.51 \\
\hline
\end{tabular}

When consistency ratio $\mathrm{CR}=\frac{C I}{R I}<0.1$, it is considered that the degree of inconsistency is within the permitted scope.

After calculation, $\mathrm{CR}=\frac{\mathrm{CI}}{\mathrm{RI}}=\frac{0.0435}{0.90}=0.048<0.1$, the $\lambda$ is within the permitted scope. After normalizing the feature vectors, the weight vector is obtained. Marked as:

$\mathrm{W}^{(1)}=(0.1998,0.5222,0.0781,0.1998)$

$\mathrm{w}^{(2)}=(0.25,0.3,0.2,0.25)$ as weight assigned to the original score.

Founding that the weight vector after analytic hierarchy process has a big gap with original weight vector, it is due to the intensity distribution is too large. In this case, we try to adjust the intensity ratio to get a more accurate weight distribution ratio.

Repeat 3 4, optimize the strength ratio.

$$
\text { Make } A=\left[\begin{array}{cccc}
1 & 1 / 2 & 2 & 1 \\
2 & 1 & 3 & 2 \\
1 / 2 & 1 / 3 & 1 & 1 / 2 \\
1 & 1 / 2 & 2 & 1
\end{array}\right]
$$


After calculation, $\mathrm{CR}=\frac{\mathrm{CI}}{\mathrm{RI}}=\frac{0.0104}{0.90}=0.0115<0.1$, so the $\lambda$ is within the permitted scope. And it has smaller error than before optimization. After normalizing the feature vectors, the weight vector is obtained. Marked as

$$
\begin{aligned}
& \mathrm{w}^{(3)}=(0.2270,0.4236,0.1223,0.2270) \\
& \mathrm{w}^{(2)}=(0.25,0.3,0.2,0.25) \text { as weight assigned to the original score. }
\end{aligned}
$$

5.1.4 The result of weight test

It can be found from the above inspection process, when the error of analytic hierarchy process shrinks gradually, the weight gained from the analytic hierarchy process is closer to the original weight. Especially the $P_{1}$ : Classroom efficiency (Sign in; Classroom performance) and $P_{4}$ : Activity participation (Discuss the answer; Brainstorming; Teacher's praise; Voting questionnaire) showing a basically consistent situation. Therefore, the weights of the two parts are determined to be consistent with the original weights of 0.25 . But for $P_{2}$ : Classroom assignments (Test; Task) and $P_{3}$ : Autonomous Learning (Video resource learning; Non video learning), the new weight is bigger than the original weight. At last, for $P_{2}$ weighted 0.4 , for $P_{3}$ weighted 0.1. Marked as: $w^{(4)}=(0.25,0.4,0.1,0.25)$.

5.1.5 Analysis of weight test results

The factors that affect the performance are clustered and divided into strong and weak grades based on Teachers' previous experience by analytic hierarchy process. We can be surer that class assignments occupy a larger proportion in student input. But the proportion of autonomous learning in student investment is less than teacher's original idea. This also reflects that students' investment in autonomous learning has not reached the expected value of teachers. And it has a bad situation.

\subsection{Take data one as an example to analyze the influence of four kinds of input factors on student achievement}

Data one: Advanced mathematics (the first volume) (124 people)

5.2.1 Cluster the original data and calculate the total score according to the new weight

Table 6 Advanced mathematics (the first volume) (124 people)

\begin{tabular}{|c|c|c|c|}
\hline Classroom efficiency & Classroom assignments & Autonomous Learning & Activity participation \\
\hline 76.25 & 26.52 & 171.88 & 152.37 \\
\hline 94.87 & 110.77 & 200.00 & 238.46 \\
\hline$\ldots \ldots$ & $\ldots \ldots$ & $\ldots \ldots$ & $\ldots \ldots$ \\
\hline 97.44 & 97.15 & 168.44 & 179.67 \\
\hline 122.95 & 114.28 & 188.59 & 192.94 \\
\hline
\end{tabular}

(Note: non percentile system)

5.2.2 Calculate the variance of the original score and study the importance of variance analysis after reducing one factor. (SPSS)

In order to explore the types of input that have the greatest impact on student achievement, we take the variance of the total score as a yardstick. After removing a student's input type, researching the variance of the total score of the remaining three types was compared with the variance of the original variance. The variance of total score $\mathrm{M}$ is the biggest, that is, it has the greatest influence on student achievement. Total score M: Classroom efficiency + Classroom assignments + Autonomous Learning + Activity participation

Total score $\mathrm{M}_{1}$ : Classroom assignments + Autonomous Learning + Activity participation

Total score $\mathrm{M}_{2}$ : Classroom efficiency + Autonomous Learning + Activity participation

Total score $\mathrm{M}_{3}$ : Classroom efficiency + Classroom assignments + Activity participation

Total score $\mathrm{M}_{4}$ : Classroom efficiency + Classroom assignments + Autonomous Learning 
Table 7 Results of variance calculation

\begin{tabular}{|c|c|c|c|c|c|}
\hline $\begin{array}{c}\text { Type of } \\
\text { achievement }\end{array}$ & $\mathrm{M}$ & $M_{1}$ & $M_{2}$ & $M_{3}$ & $M_{4}$ \\
\hline $\begin{array}{c}\text { Variance } \\
\text { results }\end{array}$ & 4391.957 & 3633.320 & 3360.767 & 2573.145 & 1854.011 \\
\hline
\end{tabular}

Calculate the impact of each factor on the total score $\mathrm{G}, \mathrm{G}_{i}=\frac{M-M_{i}}{M} \times 100 \%$, results:

Table 8 Influence of various factors

\begin{tabular}{|c|c|c|c|c|}
\hline Factor type & $P_{1}$ & $P_{2}$ & $P_{3}$ & $P_{4}$ \\
\hline Influence size & $17.273 \%$ & $23.479 \%$ & $41.412 \%$ & $57.786 \%$ \\
\hline
\end{tabular}

Analysis and calculation results, after a lack of certain factors, the total scores fluctuated in different sizes after a lack of certain factors. These different fluctuations are the reflection of the influence of each factor on the total score. We can see that the most influential factor on total score is activity participation. 5.2.3 Analysis of students' learning habits by means of mean deviation method (Excel)

When we compare horizontally each student's learning habits, we use the mean deviation method. The results of each learning input are calculated vertically, and the deviation ratio of each student's input to the average is calculated. The study habits of the students are studied.

Starting from the four types of achievements of students after clustering, calculate the average score of each type. Then make the difference between the student's original score and the average value, calculate the percentage of the difference in the average. According to the deviation reflected by the percentage, the degree of students' inclination to this type of learning is analyzed.

According to the tendency, we classify students' learning types:

Comprehensive development type: All learning types were far above average.

Balanced development type: All learning types are above average, but there are no outstanding learning types.

Fond of research type: Classroom learning is much higher than average.

Sociable type: Activity participation is much higher than average.

Passive learning type: There is little difference between the average and the different types.

Learning dissociation type: All types are far below average.

Table 9 Results of types

\begin{tabular}{|c|c|c|c|c|}
\hline Classroom efficiency & $\begin{array}{c}\text { Classroom } \\
\text { assignments }\end{array}$ & $\begin{array}{c}\text { Autonomous } \\
\text { Learning }\end{array}$ & Activity participation & \\
\hline$-25.73 \%$ & $-74.81 \%$ & $-6.00 \%$ & $-18.33 \%$ & $\begin{array}{c}\text { Learning dissociation } \\
\text { type }\end{array}$ \\
\hline$-7.60 \%$ & $5.20 \%$ & $9.39 \%$ & $27.82 \%$ & Sociable type \\
\hline$\ldots \ldots$ & $\ldots \ldots . . . .$. & $-7.82 \%$ & $\begin{array}{c}\text { Learning dissociation } \\
\text { type }\end{array}$ \\
\hline$-2.60 \%$ & $-16.82 \%$ & $-38.77 \%$ & $-3.69 \%$ & $\begin{array}{c}\text { Learning dissociation } \\
\text { type }\end{array}$ \\
\hline$-5.10 \%$ & $-7.74 \%$ & $-7.88 \%$ & $3.42 \%$ & $\begin{array}{c}\text { Balanced } \\
\text { development type }\end{array}$ \\
\hline $19.75 \%$ & $8.52 \%$ & $3.15 \%$ & & \\
\hline
\end{tabular}

Calculate the average values of the deviation values of each learning type and record the proportion of all learning types in the total population after the refinement of the data. Give the result as follows:

Table 10 Proportion of different types on four elements

\begin{tabular}{|c|c|c|c|c|c|}
\hline Student types & $\begin{array}{c}\text { Classroom } \\
\text { efficiency }\end{array}$ & $\begin{array}{c}\text { Classroom } \\
\text { assignments }\end{array}$ & $\begin{array}{c}\text { Autonomous } \\
\text { Learning }\end{array}$ & $\begin{array}{c}\text { Activity } \\
\text { participation }\end{array}$ & $\begin{array}{c}\text { Student } \\
\text { occupation ratio }\end{array}$ \\
\hline $\begin{array}{c}\text { Comprehensive } \\
\text { development type }\end{array}$ & $21.93 \%$ & $17.42 \%$ & $9.31 \%$ & $29.26 \%$ & $4.03 \%$ \\
\hline $\begin{array}{c}\text { Balanced } \\
\text { development type }\end{array}$ & $9.77 \%$ & $7.87 \%$ & $8.42 \%$ & $4.88 \%$ & $14.52 \%$ \\
\hline
\end{tabular}




\begin{tabular}{|c|c|c|c|c|c|}
\hline \multicolumn{6}{|c|}{ Cont. to Table 10} \\
\hline $\begin{array}{c}\text { Fond of research } \\
\text { type }\end{array}$ & $-0.11 \%$ & $14.84 \%$ & $5.34 \%$ & $-4.40 \%$ & $11.29 \%$ \\
\hline Sociable type & $-1.65 \%$ & $3.59 \%$ & $5.55 \%$ & $24.68 \%$ & $19.35 \%$ \\
\hline $\begin{array}{c}\text { Passive learning } \\
\text { type }\end{array}$ & $-1.50 \%$ & $-0.51 \%$ & $-3.27 \%$ & $-10.84 \%$ & $26.61 \%$ \\
\hline $\begin{array}{c}\text { Learning } \\
\text { dissociation type }\end{array}$ & $-6.50 \%$ & $-16.86 \%$ & $-9.95 \%$ & $-13.58 \%$ & $24.19 \%$ \\
\hline
\end{tabular}

(1) The proportion of comprehensive development type is $4.03 \%$. The average values of classroom efficiency, classroom assignments, autonomous learning and activity participation are the highest in all six categories.

(2) The proportion of balanced development type is $14.52 \%$. The average values of classroom efficiency, classroom assignments, autonomous learning and activity participation are slightly higher than the average level.

(3) The proportion of fond of research type is $11.29 \%$, Performance in class is outstanding, while others are near average.

(4) The proportion of sociable type is $19.35 \%$. Performance is outstanding in terms of participation in activities, and in other respects, it is near average.

(5) The proportion of passive learning type is $26.61 \%$. In the three aspects of classroom efficiency, classroom assignments and autonomous learning, they are at the average level, and they are poorer in activity participation.

(6) The proportion of learning dissociation type is $24.19 \%$. The average values of classroom efficiency, classroom assignments, autonomous learning and activity participation are the lowest in all six categories, and far below the average level.

\section{Discussion and Summary}

This study uses Mosoteach background date mining, In-school comparative analysis based on student survey data from a comprehensive university. The results of this analysis can provide a basis for the development of such university student development and academic programs. According to the above case analysis and its results, we can analyze and discuss the learning status of college students based on the differences in student input.

\subsection{In terms of student input factors}

Special teaching design based on Mosoteach, student input is divided into four aspects: classroom efficiency, classroom assignments, autonomous learning and activity participation. These four aspects are closely related to the core literacy of mathematics. Through the classroom assignments and activity participation in mobilizing students' enthusiasm for learning, exercise students' mathematical thinking.

We use the semester grades of advanced mathematics as an example. The teacher's scores are assigned as the basis for comparing the strengths and weaknesses of each factor, and each achievement factor is clustered to form four kinds of student input. Then establish a hierarchical analysis model to verify the weight of the four students' input in the student's grades. It was found that only in the aspect of autonomous learning, the theoretical weight is lower than the teacher's expected weight.

The verification shows that students' self-study is generally not up to the expectations of teachers. In the following vertical comparisons, it can also be found that the main factors affecting students' performance are reflected in the participation of activities, rather than the autonomous learning.

In the subsequent horizontal comparison, it can be found that the variance of students' autonomous learning is small and the volatility is small, indicating that the ability of students to learn independently is at a relatively flat level. Therefore, the use of innovative curriculum resources in advanced mathematics advanced courses in the Mosoteach has a small fluctuation in the use of students, or limited resources to limit the boundaries of students' self-learning.

In order to fully utilize the resources of innovative curriculum resources, the role embodied in the Mosoteach should not be limited to the "resource pool", but should be developed in the direction of a 
channel or a way. Let students reach out to broader resources through Mosoteach. On this basis, improving or even eliminating the upper limit of students' self-learning can make students have more obvious differences in their own learning.

\subsection{In terms of student learning types}

The core of the individualized training of college students is to implement different education methods for different types of students. Under the teaching system of Mosoteach, the varied teaching design can better serve different types of students. The structured design of attitude teaching is consistent.

The main problem is that there are a large number of college students in the classroom, and it is difficult to conduct effective exchanges and discussions in the classroom. Then setting up an online communication discussion platform can be more convenient for communication activities. This is good for sociable students. In this part of the students, the participation in activities is very high, and they can also get good results, which directly reflect the promotion of this kind of individualized training to improve students' performance.

To sum up, students of different types are inclined to different types of learning input. Among them, comprehensive development type, balanced development type of students can achieve better learning results. Those who did not put enough effort into their studies were less satisfied with their performance. For example, both the passive learning type and the learning dissociation type of the students are not ideal. Therefore, in the process of talent cultivation, the school can give full play to the role of self-evaluation of students, pay more attention to students' learning behavior in a more detailed manner, consider students' personalized learning needs, diagnose and guide students on this basis, create learning environment that encourages students' input in different aspects, design individualized personnel training policies, and maximize the improvement of learning results. Although the above analysis is based on an on-campus analysis conducted by a university, which provides some insights for the exploration of students' input by comparing the experience of different universities, different results may be obtained when the students' input in different universities is compared horizontally. These conclusions cannot be obtained by general descriptive statistics or simple correlation analysis. Typical correlation analysis and cluster analysis provide a different perspective by determining the differences between the relevant factors of student input and students themselves. Higher education teaching reform is developing towards a new trend of student-based, learning-centered, student-focused, and research on learning rules. The research results show that different student inputs and their learning behaviors provide an important dimension for examining the talent cultivation measures and diversity development of colleges and universities. Therefore, education data mining and learning analysis interpretation combined with typical correlation analysis and cluster analysis provide a broader perspective for the determination of relevant factors of students' investment and the exploration of learning behavior and learning rules. Through the above analysis, it is hoped that higher education researchers will pay more attention to the issues related to student input.

\section{Acknowledgment}

Key Projects of Jiangsu University's Teaching Reform: Educational reform in 2018 in Jingjiang College of Jiangsu University: Research on learning input model of Advanced mathematics, Key issues in teaching reform in Jiangsu University: Construction research on "RTE integration" Training platform for normal students' skills based on big data analysis(2017JGZD017), Jiangsu University student research project(17c479)

\section{References}

[1]. Charles. M. Legluse edited, The theory and model of instructional design[M], Educational Science Press. P691-723 
[2]. Shu Zhongmei\& Qu Qiongfei. Analysis of University Students' Learning Achievements Based on Educational Data Mining [J]. Journal of Northeast University (Social Science Edition), 2014,16(3):309-314.

[3]. Pike G R, Smart J C, Ethington C A. The Mediating Effects of Student Engagement on the Relationships between Academic Disciplines and Learning Outcomes: An Extension of Holland's Theory [J]. Research in Higher Education, 2012, 53(5): 550-575.

[4]. Shi Qiuheng\& Guo Jianpeng. An empirical analysis of the state of university students' learning status and influencing mechanism in China [J]. Education Research, 2012, 33(2): 109-121.

[5]. Zhu Hong. The influence mechanism of College Students' participation and growth-10-year data analysis of the development of Capital University Students [J]. Education Research of Tsinghua University, 2010, 31 (6): 36-43.

[6]. Zhang Na. Summary of research on learning engagement and its influencing factors at home and abroad [J]. Psychological research, 2012, 5 (02): 83-92.

[7]. Wang Shu. A Study on the Mechanism of Student's Learning Involvement Affecting Learning Achievement in Research Universities: Based on the Data Analysis of the 2009 "Survey of Chinese College Students' Learning Situation" [J]. Education Research of Tsinghua University, 2011, 32 (4): 24-32.

[8]. Shu Zhongmei\& Xu Xiaodong. Data Mining and Analysis of College Students' Satisfaction Education from the Perspective of Learning Analysis [J]. Research on Audiovisual Education, 2014, 35 (5): 39-44.

[9]. Wang Yun\& Wang Xiaoguang\& Ye Xinzhi. Student engagement: the key factor of student success [J]. Journal of Changchun University of Technology (Higher Education Research Edition), 2012, 33 (02): 74-77.

[10]. Kong Kai Ping. The concept and structure of "student input" [J]. Foreign Educational Materials, 2000 (02): 72-76.

[11]. Xu Bo. Input from college students: from theory to practice [J]. Education Research, 2013,34 (07): 147-154.

[12]. Xu Bo. Evaluation and Improvement of University Education Quality from the Perspective of Student Involvement Theory [J]. Jiangsu Higher Education, 2013 (05): 127-129.

[13]. Yu Guihong. Perspectives on Student Affairs Management in American universities. [J]. Comparative Education Research, 2013, 35 (01): 88-92.

[14]. Cen Yuhao. The Pyramid Model of College Students' Growth-Local Student Development Theory Based on Empirical Research [J]. Higher Education Research, 2016, 37 (10): 74-80.

[15]. Lu Genshu\& Liu Xiuying. Characteristics and types of student involvement in both conventional and online learning scenarios: Based on the survey data of students' learning experience in Xi'an Jiaotong University [J]. Research on Higher Engineering Education, 2017 (03): 129-136. 